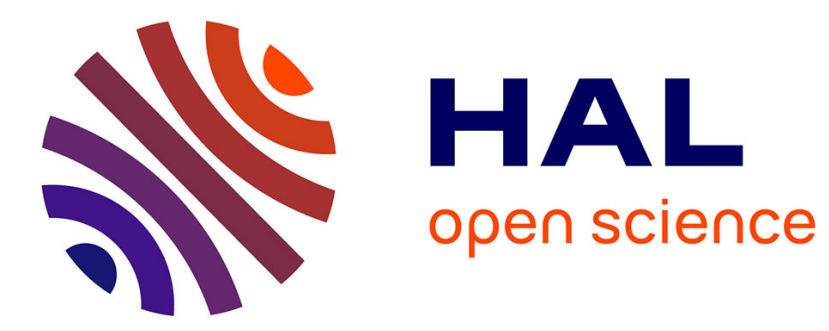

\title{
Laboratory Demonstration of a Multiterminal VSC-HVDC Power Grid
}

Sid-Ali Amamra, Frédéric Colas, Xavier Guillaud, Pierre Rault, Samuel Nguefeu

\section{- To cite this version:}

Sid-Ali Amamra, Frédéric Colas, Xavier Guillaud, Pierre Rault, Samuel Nguefeu. Laboratory Demonstration of a Multiterminal VSC-HVDC Power Grid. IEEE Transactions on Power Delivery, 2017, 32 (5), pp.2339-2349. 10.1109/TPWRD.2016.2633327 . hal-01717602

\section{HAL Id: hal-01717602 \\ https://hal.science/hal-01717602}

Submitted on 26 Feb 2018

HAL is a multi-disciplinary open access archive for the deposit and dissemination of scientific research documents, whether they are published or not. The documents may come from teaching and research institutions in France or abroad, or from public or private research centers.
L'archive ouverte pluridisciplinaire HAL, est destinée au dépôt et à la diffusion de documents scientifiques de niveau recherche, publiés ou non, émanant des établissements d'enseignement et de recherche français ou étrangers, des laboratoires publics ou privés. 


\title{
Laboratory Demonstration of a Multi-Terminal VSC-HVDC Power Grid
}

\author{
Sid-Ali AMAMRA, Frederic COLAS, Xavier GUILLAUD, Member, IEEE, Pierre RAULT \\ and Samuel NGUEFEU, Member, IEEE,.
}

\begin{abstract}
This paper presents the design, development, control and supervision of a hardware-based laboratory MultiTerminal-Direct-Current (MTDC) test-bed. This work is a part of the TWENTIES (Transmission system operation with large penetration of Wind and other renewable Electricity sources in Networks by means of innovative Tools and Integrated Energy Solutions) DEMO 3 European project which aims to demonstrate the feasibility of a DC grid through experimental tests. This is a hardware-in-the-loop DC system test-bed with simulated AC systems in real time simulation; the DC cables and some converters are actual, at laboratory scale. The laboratory scale test-bed is homothetic to a full scale high voltage direct current (HVDC) system: electrical elements are the same in per unit. The test-bed is supervised by a Supervisory Control And Data Acquisition (SCADA) system based on PcVue. Primary control based droop control method to provide DC grid power balance and coordinated control methods to dispatch power as scheduled by transmission system operator (TSO) are implemented. Since primary control acts as converter level by using local measurements, a coordinated control is proposed to manage the DC grid power flow. The implemented system is innovative and achievable for real-time, real-world MTDC-HVDC grid applications.
\end{abstract}

Index Terms-High Voltage Direct Current, Multi-Terminal DC, AC-DC grid Interactions, SCADA Supervision, Hardware In the Loop, Voltage Source Converter, Droop control, Coordinated control, DC Load-Flow, AC congestion, station outage.

\section{INTRODUCTION}

$\mathbf{E}$ UROPEAN energy policy requires both an increase of renewable production in the energy mix and the reduction of $\mathrm{CO} 2$ emissions. Integrating more wind energy in the European power system is one answer to these objectives. As new onshore sites tend to be increasingly scarce due to a reduction of potential physical space [1], [2], there is a growing interest in locating wind farms off-shore. This has made manufacturers go beyond the boundaries imposed by onshore installations and reach toward offshore challenges[3]. The use of DC transmissions to connect offshore production far from the coast (i.e. with better energy production potential) is mandatory. Historically, the main reason which led to the development of the DC technology was the transmission efficiency over long

This work is part of the TWENTIES Demo3 European project and has been funded by the 7th Framework Program (FP7) of the European Commission http://www.twenties-project.eu. It was supported financially by Réseaux de Transport Electrique - France. http://www.rte-france.com.

Sid-Ali AMAMRA, Frédéric COLAS and Xavier GUILLAUD are with Univ. Lille, Centrale Lille, Arts et Metiers Paristech, HEI, EA 2697 - L2EP, Laboratoire d'Electrotechnique et d'Electronique de Puissance, F-59000 Lille, France (Email: sidali.amamra@yncrea.fr)

Pierre RAULT and Samuel Nguefeu are with RTE National Centre for Grid Expertise Paris, France distances in terms of losses, compared with a corresponding AC transmission system, owing to no reactive power transport [4]. The willingness to integrate offshore wind farms and the improvement of DC to AC high power conversion tend to increase the field of application for DC transmissions [5]. Regarding offshore wind farms, most of the planned DC transmission systems are currently point-to-point links [6]. To achieve viability and, increase flexibility and reliability, a possible evolution would be to interconnect and even mesh the point-to-point links to finally obtain Multi-Terminal Direct Current (MTDC) systems [7], [8]. In fact, aggregating the wind power into a MTDC system contributes to balancing the regional wind power fluctuation, because the cross correlation of wind speeds in various geographical locations is much lower than within the same region [9]. However, the development of MTDC grids is a real breakthrough and remains an important technological challenge especially in terms of meshed grid. Lots of publications have already been written on these topics [10], [11], [12], and the results are mainly based on offline simulations since the development of a Multi MW demonstrator is very expensive or does not include real cables. An intermediate stage, which is proposed in this paper, is to develop a small scale actual MTDC interacting with a real time simulated AC system using a Power Hardware In the Loop (PHIL) simulation [13]. This concept makes it possible to test, with cost effectiveness, the behavior of actual devices in nearly real situations. The mock-up presented in this paper uses this PHIL principle and consists of a five-station DC network, which connects three off-shore wind farms to two on-shore terminals. Since the power electronic converters are considered as very scalable, this kind of mock-up provides the ability to validate control algorithms devoted to DC grids in a very realistic environment. As it is based on a PHIL simulation, this mock-up has been designed to test different kinds of control strategies, to assess the initialization and termination process. It is also possible to consider a communication link between stations and a SCADA system, and the topology of the grid is totally reconfigurable. Different types of experimentation may be imagined on this equipment; this paper is focused on power flow control, while the protection scheme has been dealt with in [14]. Different control schemes of the MTDC power grid have been proposed such as in [15]. In this paper, a hierarchical control strategy inspirited from an AC power system [16] has been implemented and tested. It is based on two levels: a local control level and a remote control level. In the local level, droop controllers have been used [17]. It has been demonstrated [18] that the voltage response time depends 
on the converter station capacitors (i.e. electrostatic constant), on the droop parameter $k$ and on the number of stations which control the DC voltage $m$. A novel methodology to design the droop parameter is presented. It is based on voltage control loop response time and final voltage deviation choices, and takes into account the number of substations which participate, or not, in the voltage control. However, the main weakness of droop control is that power-flow dispatch is not perfectly controlled. A remote control level is then mandatory to improve power-flow dispatch. A master controller based on coordinated control with a modified NewtonRaphson load flow algorithm has been implemented for that. Following the system operator's orders and the scheduled power transmissions, the master controller sends references to all DC grid devices. It takes into account the voltage drops and transmission losses to send suitable converter settings in order to achieve a precise power flow control. It can also communicate with the TSO of the connected AC grid to alleviate AC congestion. The Numerical method to calculate steady state operating points to find suitable set points for DC grid devices is presented. The main contributions of this paper are: - Firstly: The development of a laboratory scale five-station/five-line MTDC grid to reflect at best the expected behavior of a future HVDC grid, to provide enough flexibility to test different DC and AC network topologies and to compare different control laws based on actual DC cables. - Secondly: The development and integration of a real-time control and supervision system based on an association of a local and a remote control level. The remainder of this paper is organized as follows: The proposed DC system configuration and modeling is provided in section II. Section III describes the proposed local and master controllers of the MTDC grid. Conclusions are summarized in Section IV.

\section{CONFIGURATION AND MODELING OF THE PROPOSED SYSTEM}

An overview of the five-terminal DC grid test-bed is presented in Fig. 1.

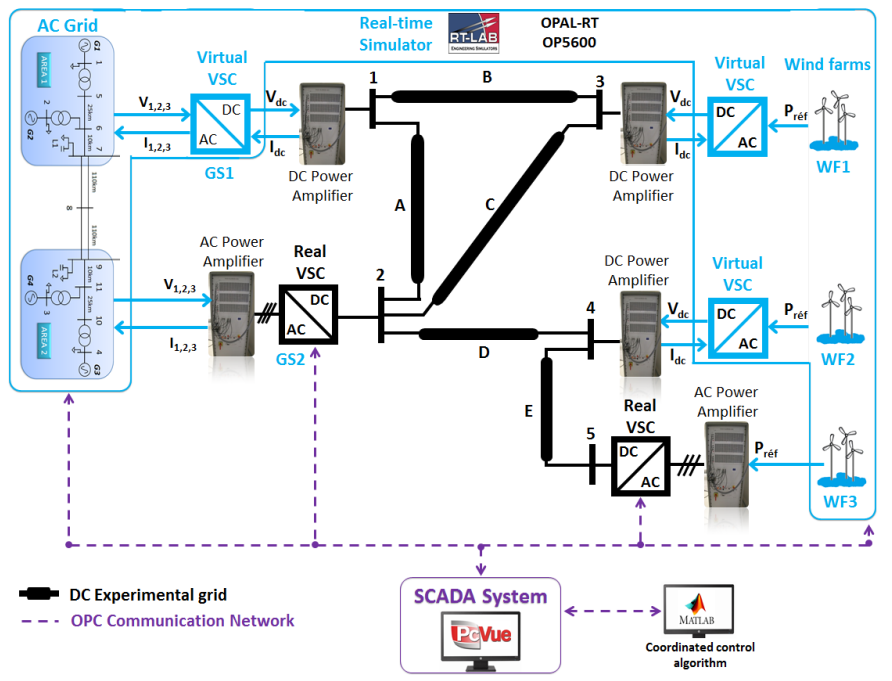

Fig. 1. Test-bed general overview
The test-bed is divided in two main parts; one physical part in the center of the figure in black and one virtual part simulated and implemented in Opal-RT ${ }^{\circledR}$ real-time simulator in blue. The interface between physical devices and the real time simulator analog outputs with two solutions:

- Actual two-level VSC connected to the real time simulator with three-phased AC power amplifier

- Virtual two-level VSC connected to the DC grid with DC power amplifier

The grid is composed of low voltage DC cables composed of two symmetrical poles. The AC grid, wind farms and virtual VSCs are simulated in the real-time simulator. Finally, the DC system is monitored and controlled by a SCADA system called PcVue, which receives information from VSCs or the real-time simulator and then sends set points to them thanks to an OPC communication protocol.

\section{A. Laboratory scale of HVDC grid}

To better reflect the behavior of a high voltage DC grid, special attention was paid during the design process to have a homothetic design of the major components constituting the DC grid.

1) Converter station design and control: Converter stations used in the test-bed are classical 2-level converters associated with an LCL filter for mitigating the current harmonics on the AC side, and a DC capacitor and smoothing reactors on the DC side Fig. 2.

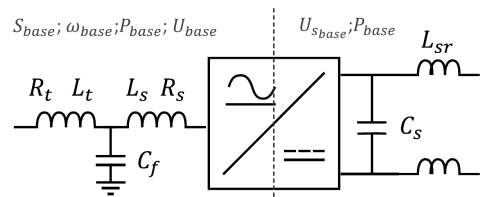

Fig. 2. Validation of the VSC scaling methodology

The equivalence between high power converter and the testbed converter can be easily achieved thanks to the per unit transformation. It has been demonstrated that energy stored in the DC system characterizes its dynamics. AC system dynamics are characterized by the kinetic energy stored in synchronous rotating machines connected to it. For DC systems, the energy is stored in an electrostatic form since it corresponds mainly to the energy stored in converter station capacitors; this stored energy could be expressed by:

$$
E_{C}=\frac{1}{2} C_{S} u_{S}^{2}
$$

Where:
$u_{S}$
$C_{S}$
$E_{S}$

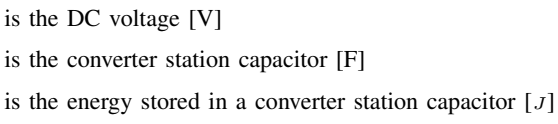

The same approach can be applied for the smoothing reactor design:

$$
E_{L}=\frac{1}{2} L_{S} I_{\text {base }}^{2}
$$


TABLE I

PER UNIT APPROACH FOR CONVERTER STATION DESIGN

\begin{tabular}{|l|l|l|c|c|}
\cline { 2 - 5 } & Parameters & $\begin{array}{c}\text { High power } \\
\text { converter }\end{array}$ & $\begin{array}{c}\text { Per } \\
\text { unit }\end{array}$ & $\begin{array}{c}\text { Test-bed } \\
\text { converter }\end{array}$ \\
\hline \multirow{5}{*}{ AC side } & $S_{\text {base }}$ & $1077 \mathrm{MVA}$ & 1 p.u. & $3 \mathrm{kVA}$ \\
\cline { 2 - 5 } & $\mathrm{U}_{\text {base }}$ & $230 \mathrm{kV}$ & 1 p.u. & $125 \mathrm{~V}$ \\
\cline { 2 - 5 } & $\begin{array}{l}\text { LCL } \\
\text { cut-off } \\
\text { frequency }\end{array}$ & $500 \mathrm{~Hz}$ & - & $1 \mathrm{kHz}$ \\
\cline { 2 - 5 } & $\mathrm{R}_{S}$ & $0.48 \Omega$ & 0.005 p.u. & $0.026 \Omega$ \\
\cline { 2 - 5 } & $\mathrm{L}_{S}$ & $45 \mathrm{mH}$ & 0.15 p.u. & $2.5 \mathrm{mH}$ \\
\cline { 2 - 5 } & $\mathrm{R}_{t}$ & $0.48 \Omega$ & 0.005 p.u. & $0.026 \Omega$ \\
\cline { 2 - 5 } & $\mathrm{L}_{t}$ & $45 \mathrm{mH}$ & 0.15 p.u. & $2.5 \mathrm{mH}$ \\
\cline { 2 - 5 } & $\mathrm{C}_{f}$ & $4.47 \mu \mathrm{F}$ & - & $20.4 \mu \mathrm{F}$ \\
\hline \multirow{5}{*}{ DC side } & $\mathrm{U}_{\text {s base }}$ & $640 \mathrm{kV}$ & 1 p.u. & $250 \mathrm{~V}$ \\
\cline { 2 - 5 } & $\mathrm{P}_{\text {base }}$ & $1000 \mathrm{MW}$ & 1 p.u. & $2.5 \mathrm{~kW}$ \\
\cline { 2 - 5 } & $\mathrm{C}_{s}$ & $50 \mu \mathrm{F}$ & $10.24 \mathrm{~ms}$ & $819 \mu \mathrm{F}$ \\
\cline { 2 - 5 } & $\mathrm{L}_{S R}$ & $10 \mathrm{mH}$ & $1.10^{-2} \mathrm{~ms}$ & $610 \mathrm{mH}$ \\
\hline
\end{tabular}

Where:

$I_{\text {base }} \quad$ is the AC current [A]

$L_{S} \quad$ is the converter station inductance $[\mathrm{H}]$

$E_{L} \quad$ is the energy stored in a converter station inductor [J]

Physical converter stations on the mock-up are rated at 3 $\mathrm{kVA} / 125 \mathrm{~V}-2.5 \mathrm{~kW} / 250 \mathrm{~V}$. Their design is based on data from a 1077 MVA - $1000 \mathrm{MW}$ converter station [2]. Passive component values are summarized in Table I. Fig. 3 A,B and $\mathrm{C}$ show three types of power-voltage control strategies for the VSC, i.e. characteristics implemented to control VSC (constant power, constant voltage or droop control). In order to validate the scaling methodology, the same simple off-line simulation is carried out for the high and low voltage converters.
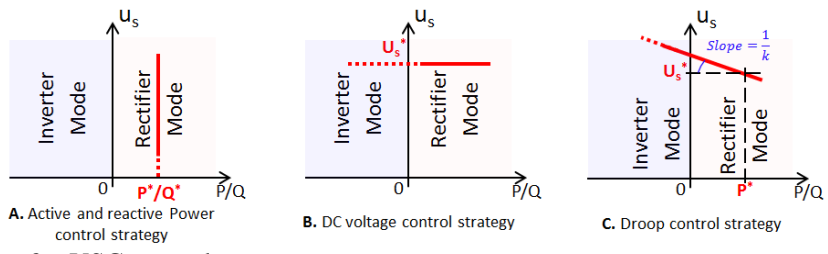

Fig. 3. VSC control strategy

Fig. 4 shows, in per unit, the comparison results from the low-voltage converter and from its high voltage. Power and voltage curves from the simulation of each converter are very similar; therefore the scaling methodology is validated. Two physical two-level VSCs based on the aforementioned methodology have been developed. It is based on the IGBT module [19]. The low level control has been implemented on a DSP card [19]. The gateway with the SCADA system is ensured by a Beckhoff PLC.

2) DC cable design and modeling: The DC cable should ensure wave propagation, hence it is not possible to emulate the DC cable by a simple RLC circuit, such as $\Pi$ equivalent

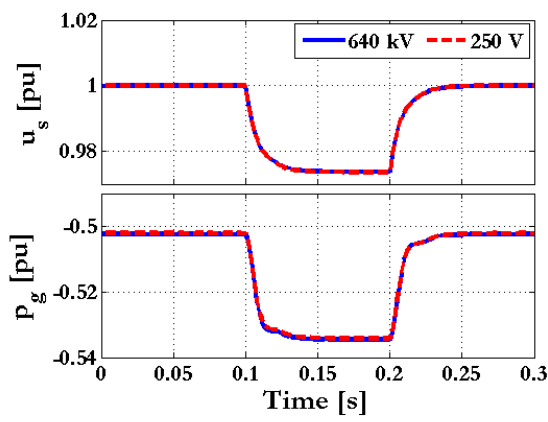

Fig. 4. Validation of the VSC scaling methodology

[20]. Therefore, the DC cable is emulated by a laboratoryscale coaxial cable, to have a similar propagation time as a corresponding high voltage cable. The copper section of the core was chosen to achieve a voltage drop smaller than $5 \%$ per cable for a current of $10 \mathrm{~A}$ and a nominal voltage of 250 $\mathrm{V}$. Nexans has proposed using cables with copper sections of $10 \mathrm{~mm}^{2}$ and $25 \mathrm{~mm}^{2}$ which leads to a maximal length of $2 \mathrm{~km}$ and $5 \mathrm{~km}$, to stay within the voltage bounds. As these cables must be installed in a limited space and for economic reasons, their total length has been limited to $15 \mathrm{~km}$ (i.e. 7.5 per pole).

It is known that the first resonance in the classical $\Pi$ model appears at a lower frequency than the Wide-band Model [21]. The Highest frequency limit of model validity is $20 \mathrm{~Hz}$, too narrow a band compared with the current loop dynamics. To overcome this problem, a little more sophisticated model is introduced. The new model takes into account the coupling between the core and the screen Fig. 5 .

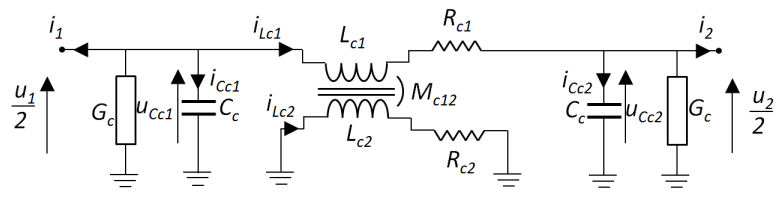

Fig. 5. Positive pole of the $\Pi$ core-screen coupled model

In the following, the state space model of this special $\Pi$ section is presented. The pole's differential equations are:

$$
\begin{gathered}
\frac{d u_{C c 1}}{d t}=\frac{1}{C_{c 1}} i_{C c 1} \\
\frac{d u_{C c 2}}{d t}=\frac{1}{C_{c 2}} i_{C c 2} \\
\Phi_{1}=L_{c 1} i_{L c 1}+M_{c 12} i_{L c 2} \\
\Phi_{2}=L_{c 2} i_{L c 2}+M_{c 21} i_{L c 1} \\
u_{L c 1}=\frac{d \Phi_{1}}{d t}=L_{c 1} \frac{d i_{L c 1}}{d t}+M_{c 12} \frac{d i_{L c 2}}{d t} \\
u_{L c 2}=\frac{d \Phi_{2}}{d t}=L_{c 2} \frac{d i_{L c 2}}{d t}+M_{c 21} \frac{d i_{L c 1}}{d t}
\end{gathered}
$$

We can obtain a four-order system which represents the pair of cables by arranging these equations. 
The cables used to represent the DC grid are a laboratory scale technology of the actual DC cables. The cables are kept on their cable drums to increase their linear inductance and boost the propagation speed Fig. 6. In this configuration, the linear inductance for each line has been measured, and the propagation speed has been calculated. Table II summarizes the actual high voltage DC cable (left value) and the test-bed DC cable (right value) characteristics.

The theoretical wave speed through a coaxial cable is given by the well-known formula:

$$
\sigma=\frac{1}{\sqrt{L C}}
$$

TABLE II

High Voltage(Left Value) AND Test-Bed (Right VAlue) DC CABle CHARACTERISTICS

\begin{tabular}{|c|c|c|c|c|c|c|}
\hline Link & $\begin{array}{l}\text { Cable } \\
\text { section } \\
{\left[\mathrm{mm}^{2}\right]}\end{array}$ & $\begin{array}{c}\text { Total } \\
\text { Cable length } \\
{[\mathrm{km}]}\end{array}$ & $\begin{array}{c}\text { Total } \\
\text { resistance } \\
{[\Omega]}\end{array}$ & $\begin{array}{c}\text { Total } \\
\text { inductance } \\
{[\mathrm{mH}]}\end{array}$ & $\begin{array}{c}\text { Total } \\
\text { capacitance } \\
{[\mu F]}\end{array}$ & $\begin{array}{c}\text { Propagation } \\
\text { time } \\
{[\mu s]}\end{array}$ \\
\hline $\mathbf{A}$ & \multirow{4}{*}{$1.5410^{4} / 25$} & $25 / 0.45$ & $0.38 / 0.43$ & $2.40 / 17.3$ & $6.79 / 0.19$ & 126.4 / 57 \\
\hline B & & $50 / 1.14$ & $0.76 / 1.01$ & $4.70 / 43.1$ & $1.35 / 0.47$ & $252.8 / 142$ \\
\hline C & & $75 / 1.82$ & $1.13 / 1.46$ & $7.10 / 69.0$ & $2.04 / 0.74$ & $379.2 / 228$ \\
\hline D & & $100 / 2.27$ & $1.15 / 1.77$ & $9.40 / 86.3$ & $2.71 / 0.93$ & $505.6 / 285$ \\
\hline $\mathbf{E}$ & $1.5410^{4} / 10$ & $100 / 1.45$ & $1.15 / 2.52$ & $9.40 / 58.7$ & $2.71 / 0.46$ & $505.6 / 570$ \\
\hline
\end{tabular}

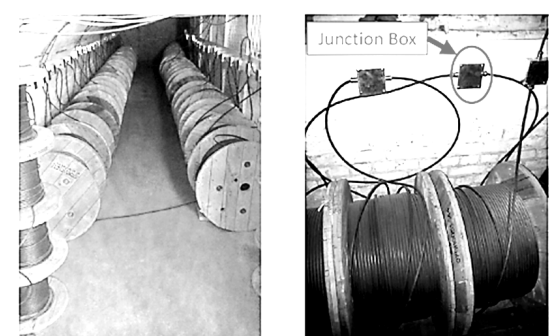

Fig. 6. Cable-laying (left: cable drums arrangement, right: junction between two cables)

\section{B. Test-bed storage and Power flow}

Capacitors are key components for the DC grid dynamics; consequently special attention has been paid to have homothetic capacitor values.

TABLE III

IMPLEMENTED STATION CAPACITORS

\begin{tabular}{|c|c|c|c|c|c|c|}
\hline & Type & $\begin{array}{c}\text { Nominal } \\
\text { DC Voltage } \\
{[V]}\end{array}$ & $\begin{array}{c}\text { Nominal } \\
\text { Power } \\
{[W]}\end{array}$ & $\begin{array}{c}\text { Electrostatic } \\
\text { constant } \\
{[\mathrm{ms}]}\end{array}$ & $\begin{array}{c}\text { Desired } \\
\text { capacitor value } \\
{[\mu F]}\end{array}$ & $\begin{array}{c}\text { Capacitor } \\
\text { value } \\
{[\mu F]}\end{array}$ \\
\hline $\mathbf{G} S_{1}$ & Virtual & \multirow{5}{*}{250} & 2200 & \multirow{5}{*}[mod]{} & 721 & 721 \\
\hline $\mathbf{G} S_{2}$ & Physical & & 2600 & & 852 & $1100 \pm 20 \%$ \\
\hline $\mathbf{W} F_{1}$ & Virtual & & 2400 & & 786 & 786 \\
\hline $\mathbf{W} F_{2}$ & Virtual & & 1320 & & 433 & 440 \\
\hline $\mathbf{W} F_{3}$ & Physical & & 850 & & 279 & $270 \pm 20 \%$ \\
\hline
\end{tabular}

As said above, test-bed converter station capacitors are designed to have the same electrostatic constant as a unitary scale VSC (i.e. around $10 \mathrm{~ms}$ ) [19]. From the nominal power of converter stations and a $10 \mathrm{~ms}$ electrostatic constant, the desired capacitor values are presented in Table III. However, it is not possible to get the exact capacitor values for physical converters (Node 2 and Node 5) since capacitors are sold as normalized values. It should also be pointed out that physical capacitors have a tolerance of $20 \%$.
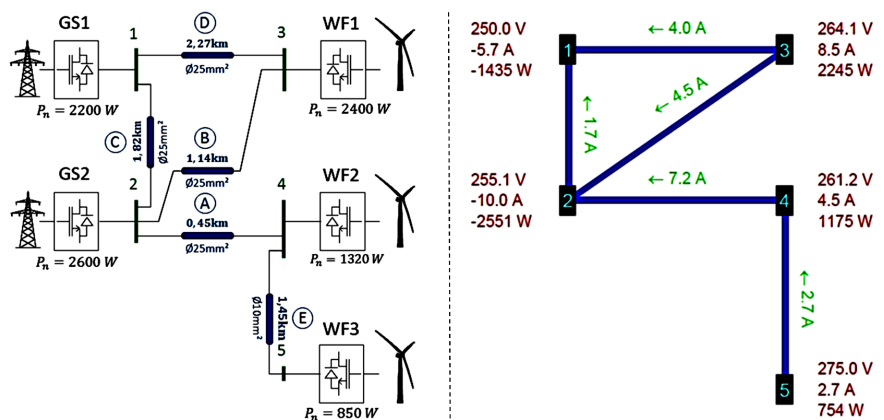

Fig. 7. Test-bed cable arrangement (left) and DC power flow overview(right)

The nominal power of each station has been obtained from a specific scenario performed on the test-bed. It is required that the voltage deviation between the highest voltage level and the lowest voltage level should be below $10 \%$ in normal operations. Thanks to the steady state algorithm and cable data directly measured on the test-bed, a scenario which satisfies the voltage drop requirements has been found. To obtain this scenario, $\mathrm{GS}_{1}$ has been set at the nominal voltage level (i.e. $250 \mathrm{~V})$, and $\mathrm{WF}_{3}$ has been set at the highest voltage level (i.e. $275 \mathrm{~V}$ ). The current through $\mathrm{GS}_{2}$ has been imposed at $10 \mathrm{~A}$, and currents from $\mathrm{WF}_{1}$ and $\mathrm{WF}_{2}$ have been defined at 8.5 A and 4.5 A respectively to get a convenient power flow. The power flow is shown in Fig. 7 (right). This scenario has been considered to define the nominal power of each converter station. The nominal power of each station is sized close to the power flow scenario, apart from $\mathrm{GS}_{1}$ which is powerful enough to be able to take part of the power currently delivered to the $\mathrm{AC}$ grid by $\mathrm{GS}_{2}$. The nominal apparent power is sized $5 \%$ higher than the nominal real power(Table IV).

TABLE IV

TEST-BED LOAD FLOW AND STATION NOMINAL POWER

\begin{tabular}{|c|c|c|c|c|c|}
\cline { 2 - 6 } \multicolumn{1}{c|}{} & $\begin{array}{c}\text { DC } \\
\text { Voltage } \\
{[V]}\end{array}$ & $\begin{array}{c}\text { DC } \\
\text { Currents } \\
{[A]}\end{array}$ & $\begin{array}{c}\text { Real } \\
\text { Power } \\
{[W]}\end{array}$ & $\begin{array}{c}\text { Nominal } \\
\text { Real Power } \\
{[W]}\end{array}$ & $\begin{array}{c}\text { Nominal } \\
\text { apparent power } \\
{[V A]}\end{array}$ \\
\hline $\mathbf{G} S_{1}$ & 250 & -5.7 & -1435 & 2200 & 2310 \\
\hline $\mathbf{G} S_{2}$ & 255 & -10 & -2551 & 2600 & 2730 \\
\hline $\mathbf{W} F_{1}$ & 264 & 8.5 & 2245 & 2400 & 2520 \\
\hline $\mathbf{W} F_{2}$ & 261 & 4.5 & 1175 & 1320 & 1386 \\
\hline $\mathbf{W} F_{3}$ & 275 & 2.7 & 754 & 850 & 892.5 \\
\hline
\end{tabular}

\section{Real time simulated AC system}

In order to show how the DC grid can participate in $\mathrm{AC}$ ancillary services, converter stations are connected to the AC grid. It has been simulated in real time in the Opal-RT ${ }^{\circledR}$ simulator. In this system, the simulated AC grid deals with hundreds of megawatts while the test-bed deals with thousands of watts. To face this problem, a scale factor is considered between the power extracted from the DC grid 
and the one injected into the $\mathrm{AC}$ grid. In the simulated $\mathrm{AC}$ grid, grid-side converter stations are replaced by power injector sources.

The three wind farms are simulated. It consists of French onshore wind farm profile data, adjusted to the test-bed nominal power constraint and accelerated in time.

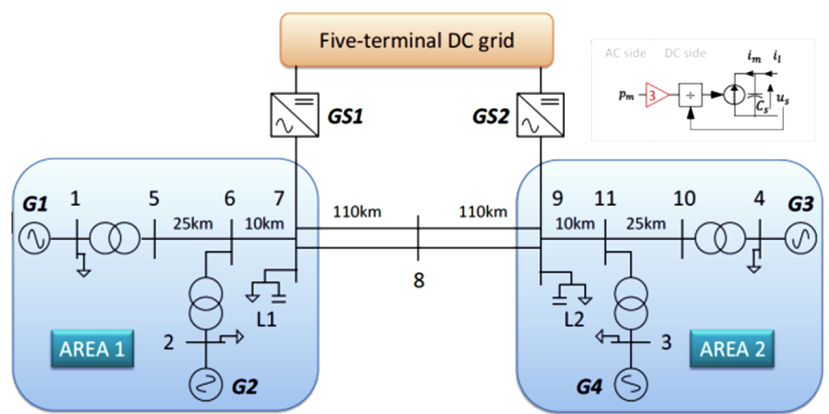

Fig. 8. AC test system connected to test-bed DC through PHIL

The considered AC system, named Kundur grid [16], is presented in Fig. 8. It is a well-known two-area system studied for inter-area oscillations. In this work the $\mathrm{AC}$ test system is connected to the five-terminal DC grid, and $\mathrm{GS}_{1}$ and $\mathrm{GS}_{2}$ are connected to node 7 and 9 respectively of the $\mathrm{AC}$ grid, as shown in Fig. 8.

D. Test-bed supervision based SCADA system and Test-bed signal management

The SCADA system based on PcVue soft is used; it acts as a dispatching center and is able to:

- Monitor quantities of each converter station and states of each component,

- Change the control mode of each converter station,

- Send references to each station's local controller,

- Send suitable converter set points to reach a desired power flow,

- Automatically recalculate converter orders after an event to return to normal operations,

- Monitor and control AC grids,

- Start and stop wind power production,

The test-bed communication scheme is presented in Fig. 9.

The communication between devices is done through an Ethernet network. The communication protocol OPC was chosen to achieve the communication between multivendor devices: PcVue server, Beckhoff PLC, the OPAL-RT ${ }^{\circledR}$ and other client computers. A Beckhoff PLC is embedded in each converter station to be employed as a gateway between a home-made protocol over RS232 serial communication and the OPC over the Ethernet network. The latency of the SCADA system is 1s. Each station receives power and voltage references and returns voltage and current measurements to the SCADA system; Master controller based DC load flow algorithm is implemented in client computers and communicates with SCADA through OPC.

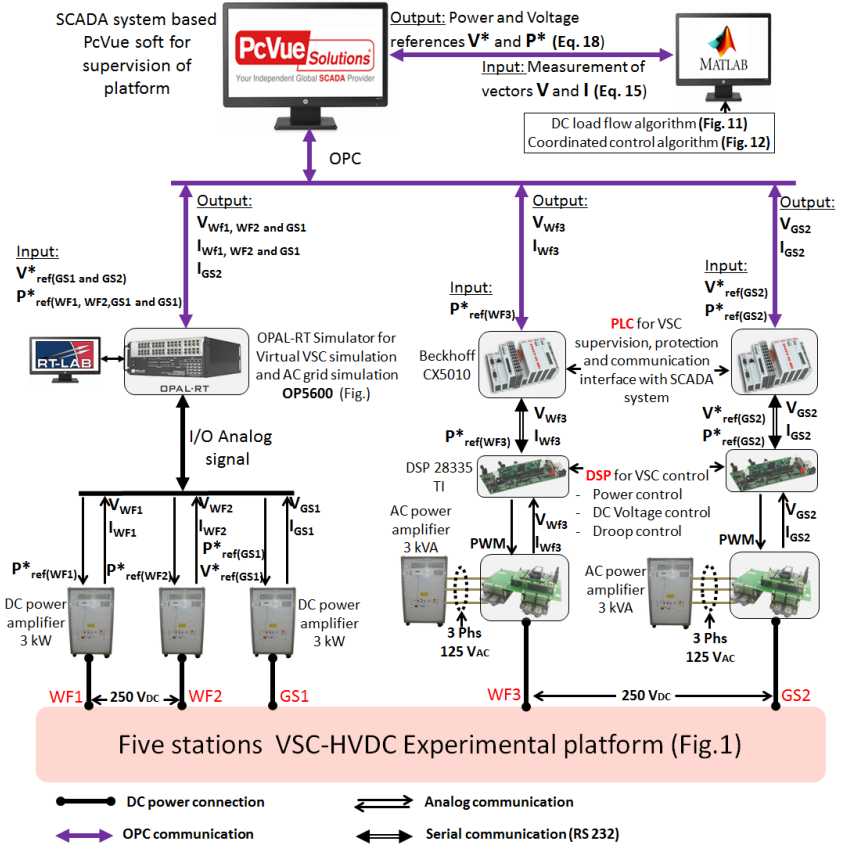

Fig. 9. Test-bed communication scheme

\section{CONTROL AND SUPERVISION OF THE PROPOSED SYSTEM}

\section{A. Assessment of droop control}

In this work, a methodology to design the droop value is proposed. It has been seen in simulation that the voltage response time depends on the converter station capacitors, on the droop parameter $k$ and on the number of stations which control the DC voltage $m$ [22], [23]. Moreover, the voltage deviation which comes from a given power deviation is defined by the droop value $k$ and $m$. The choice of the voltage droop parameter is a trade-off between response time and final voltage deviation. However, the DC voltage control loop is an outer control loop embedding the current control loop. Therefore, system stability is improved when the voltage control loop is slower. Based on this consideration, the droop value was sized to achieve a desired response time. The droop value was chosen with:

$$
k=\frac{\tau}{2 H_{c}}\left(\frac{\sum_{j=1}^{m} P_{n j}}{\sum_{j=1}^{n} P_{n j}}\right)
$$

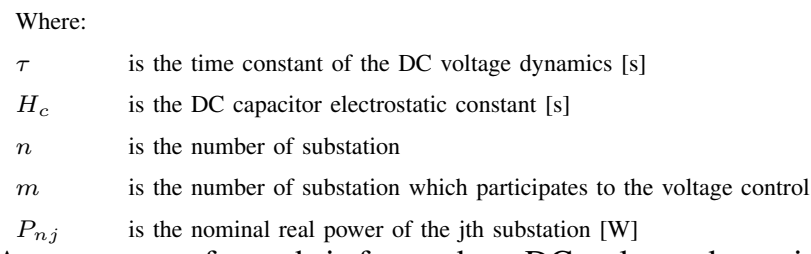

A test was performed; it focused on DC voltage dynamics when the DC grid is subjected to a severe power change. The objective is to assess the simulation model. To do this, the DC system is first stabilized at an operating point, and then; a fast power reference change is applied at $\mathrm{WF}_{1}$. For this test, $\mathrm{GS}_{1}$ and $\mathrm{GS}_{2}$ are droop controlled with a droop value set at 0.82 $\mathrm{pu} / \mathrm{pu}$ (calculated from eq. 10 and Table IV). Before the power step change in $\mathrm{WF}_{1}$, power and DC voltage references of $\mathrm{GS}_{1}$ 
are $0.25 \mathrm{pu}$ and $1 \mathrm{pu}$ respectively. The power and DC voltage references for $\mathrm{GS}_{2}$ are $0.17 \mathrm{pu}$ and $1.02 \mathrm{pu}$ respectively. The power references of $\mathrm{WF}_{1}, \mathrm{WF}_{2}$ and $\mathrm{WF}_{3}$ are $-0.25 \mathrm{pu},-0.23 \mathrm{pu}$ and -0.27 pu respectively.
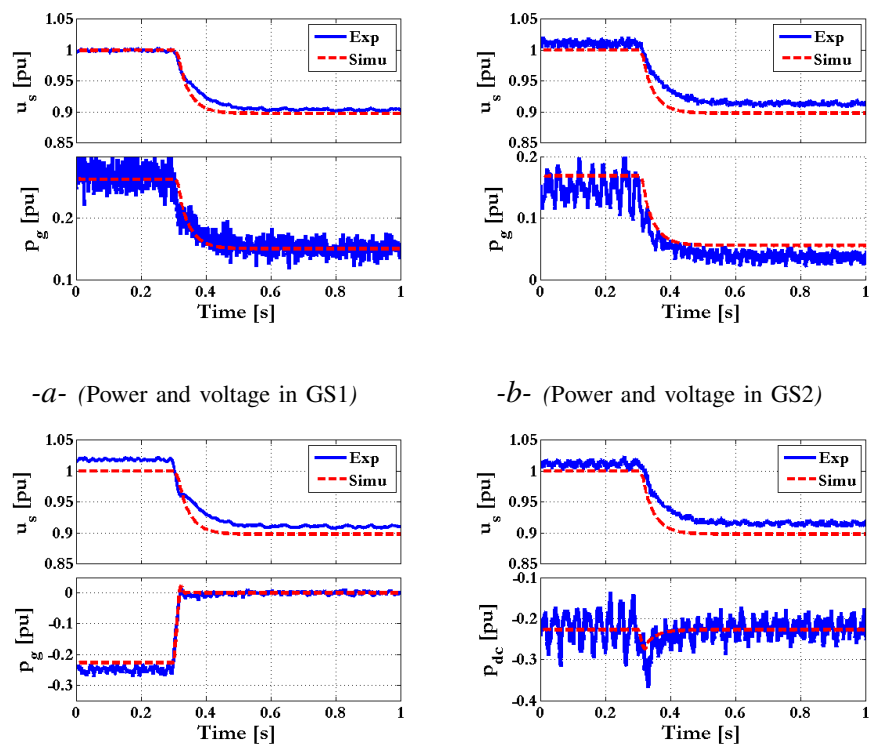

$-c$ - (Power and voltage in WF1)

$-d$ - (Power and voltage in WF2)

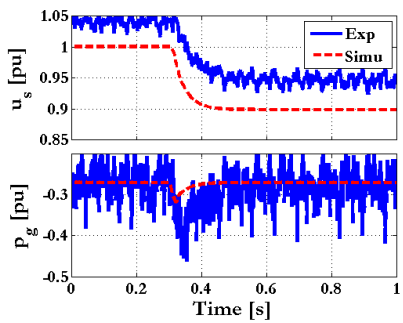

$-e$ - (Power and voltage in WF3)

Fig. 10. Experimental and simulation results of a step power change of 0.25 pu on $\mathrm{WF}_{1}$

The scenario is a sudden power reference change from -0.25 $\mathrm{pu}$ to $0 \mathrm{pu}$ at $\mathrm{WF}_{1}$. The change rate of the reference is limited at 13 pu/s. In Fig.10 (a,b,c,d and e) the power and voltage of all converter stations are reported. For $\mathrm{GS}_{1}, \mathrm{GS}_{2}$ and $\mathrm{WF}_{1}$ the power is measured on the $\mathrm{AC}$ side, while for $\mathrm{WF}_{2}$ and $\mathrm{WF}_{3}$, power is measured on the DC side.

The power and voltage are stable before the power variation (before $0.3 \mathrm{~s}$ ). The power ramp variation on $\mathrm{WF}_{1}$ is visible in Fig.10-c. In Fig.10-a and Fig.10-b, the power balance is achieved by both grid-side converter stations $\left(\mathrm{GS}_{1}\right.$ and $\left.\mathrm{GS}_{2}\right)$ with similar proportions. Since the power variation leads to a power deficit, the DC voltage level decreases and stabilizes at a lower value. The DC voltage dynamics are around the expected $100 \mathrm{~ms}$ response time.

An offline simulation has been carried out with the testbed parameters and with an equivalent $640 \mathrm{kV}$ MTDC grid using model cable presented in Fig. 5 in order to validate the models. Simulation results are displayed in red dotted lines and compared to experimental results; they are compared in per unit. The dynamics of both voltage and power are very close; the small difference comes from the capacitors of actual converters which cannot be set exactly at the designed value because of the standardized capacitor values. The voltage and power deviations are very similar.

\section{B. Assessment of the coordinated control}

For static calculations, the DC grid is only represented by its resistive elements. The studied topology is presented in Fig.11. Conductor cable losses are represented by a series resistance $\left(R_{i j}\right)$ and insulation losses by a shunt resistance $\left(R_{i i}\right)$.

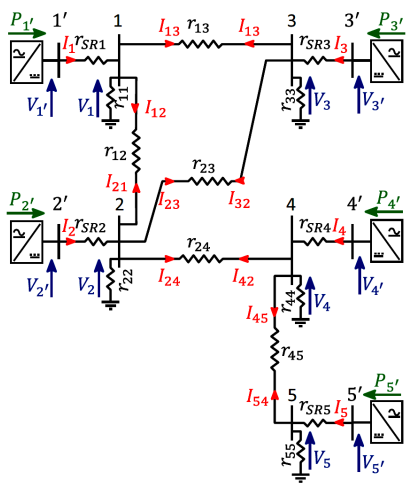

Fig. 11. Static representation of the proposed DC grid topology

The cable conductance is split and equally distributed at the two cable ends. The shunt resistance at each terminal represents the sum of half-conductance of connected cables. In this figure the losses of the smoothing reactor are also taken into account $\left(R_{i S R i}\right)$.

At each terminal, the injected current is defined as follows:

$$
I_{i}=\sum_{\substack{j=1 \\ j \neq i}}^{n} \frac{1}{R_{i j}}\left(V_{i}-V_{j}\right)+\frac{V_{i}}{R_{i i}}
$$

$$
\begin{array}{ll}
\text { Where } & \\
I_{i} & \text { is the injected current at the } i^{t h} \text { terminal } \\
V_{j} & \text { is the voltage at } j^{t h} \text { terminal } \\
n & \text { is the node number }
\end{array}
$$

Considering the whole DC grid, the previous relation can be written in a matrix form:

$$
I=Y \cdot V
$$

$$
\begin{array}{ll}
\text { Where } & \\
I & \text { is a vector containing injection currents } \\
Y & \text { is the admittance matrix } \\
V & \text { is a vector containing node voltages }
\end{array}
$$

The admittance matrix $\mathrm{Y}$ can be expressed by:

$$
\left\{\begin{array}{l}
Y_{i j}=-\frac{1}{R_{i j}} \quad \forall(i \neq j) \\
Y_{i i}=\sum_{k=1}^{n} \frac{1}{R_{i k}}
\end{array}\right.
$$

TSOs deal with power instead of currents since they manage energy transfer. Load flow programs are used for this purpose; they solved the following non-linear formula: 


$$
P=V . I=V \cdot(Y . V)
$$

Using the classical load flow algorithm based NewtonRaphson algorithm [24], all power uncertainties are borne by the constant voltage bus. For both primary control and secondary control in the AC system, it seems better to divide this power deviation among more than one converter station. Therefore; a modified Newton-Raphson load flow algorithm is proposed in order to dispatch the power mismatch between several substations, in accordance with the predefined power sharing coefficient called "participation to the coordinated control".

This algorithm has the ability to find a new set of points in order to share the wind power forecast error to several onshore converter stations, to share the power deviation due to unavailability of one converter station and to limit the wind power injection if on-shore converter stations cannot accept more power.

To fulfill this task, a new term related to power deviation is added to the power reference of each station. All converter stations have an initial power reference $\left(P^{*}\right)$, and some of them can adjust their reference to balance the DC grid power flow. The final power delivered by converter stations is given by the following formula:

$$
P=P^{*}+\frac{\alpha}{\sum \alpha} P_{d e v}
$$

$$
\begin{array}{ll}
\text { Where: } & \\
P & \text { is a vector containing delivered power } \\
P^{*} & \text { is a vector containing initial power references } \\
& \text { of all nodes including the constant voltage node } \\
\alpha & \text { is a vector containing the relative participation of each station } \\
P_{\text {dev }} & \text { is the power balance error }
\end{array}
$$

Unlike the classic method, the power flow of power controlled nodes cannot be guaranteed if their $\alpha$ parameter is not null $\left(\alpha_{i} \neq 0\right)$. Depending on the value of $\alpha_{i}$, part of the power balance error is allocated to this node. The power balance error is a new unknown which must be solved by a modified load flow algorithm.

When the system operator wants all the wind power harvested to be carried to shore, the power reference vector $\left(P^{*}\right)$ is filled by the actual wind power production $\left(P_{W F}^{*}\right)$ for wind farm converter stations and by the planned power transfer $\left(P_{G S}^{*}\right)$ for grid-side converter stations. The power balance error is shared according to the participation $\alpha$ into the coordinated control. The participation of a given station depends on the participation of other stations, i.e. the higher the $\alpha$ coefficient of a station, the larger the portion of the power deviation taken by this station. The stations which have a null participation parameter act as conventional power nodes. The particular case where there is only one converter which has a non-null $\alpha$ parameter is similar to the previous DC load flow.

The DC load flow must be adapted to take into account the new unknown $\left(P_{d e v}\right)$. Eq. 16 shows the mismatched power vector:

$$
\triangle P^{(k)}=\left(P^{*}+\frac{\alpha}{\sum \alpha} P_{d e v}^{(k)}\right)-\left(V^{(k)} \cdot Y V^{(k)}\right)
$$

The correction of the new unknown $\left(\Delta P_{\text {dev }}\right)$ is introduced into the correction vector as follows:

$$
\left[\begin{array}{c}
\triangle P_{\text {dev }}^{(k)} \\
\left(\frac{\triangle V}{V}\right)_{\left(i_{d x N V}\right)}^{(k)}
\end{array}\right]=\left(J^{(k)}\right)^{-1} \triangle P^{(k)}
$$

$$
\begin{array}{ll}
\text { Where } & \\
\triangle P_{d e v}^{(k)} & \text { is the power deviation correction }\left(0 \leq\left|\triangle P_{d e v}^{(k)}\right| \leq \triangle P_{\text {dev } \max }\right) \\
\left(i_{d x N V}\right) & \text { is the indexes of not fixed voltage nodes }
\end{array}
$$

To solve this linear system, the Jacobian is also modified. Partial derivatives of the first column express the sensitivity of the power deviation on the node mismatched power. They are defined as follows:

$$
J_{i 1}=\frac{\partial P_{i}}{\partial P_{d e v}}=-\frac{\alpha_{i}}{\sum \alpha}
$$

The flow chart of the load flow is presented in Fig. 12. The inputs of the program are the DC network admittance matrix $(Y)$, the power reference vector $\left(P^{*}\right)$, the power sharing vector $(\alpha)$ and the initial voltage vector $\left(V^{(0)}\right)$, while the outputs are the updated voltage vector $(V)$ and the power injection vector $(P)$.

The scheme of the coordinated control is shown in Fig. 13. The coordinated control calculates new references after a given time (i.e.cyclical operation) or is triggered just after a disruption, such as over-voltage. The TSO preferences are considered. They include the actual wind power production, the power transmission schedule and the desired power deviation sharing. Then, a new load flow is achieved in order to have new set points.

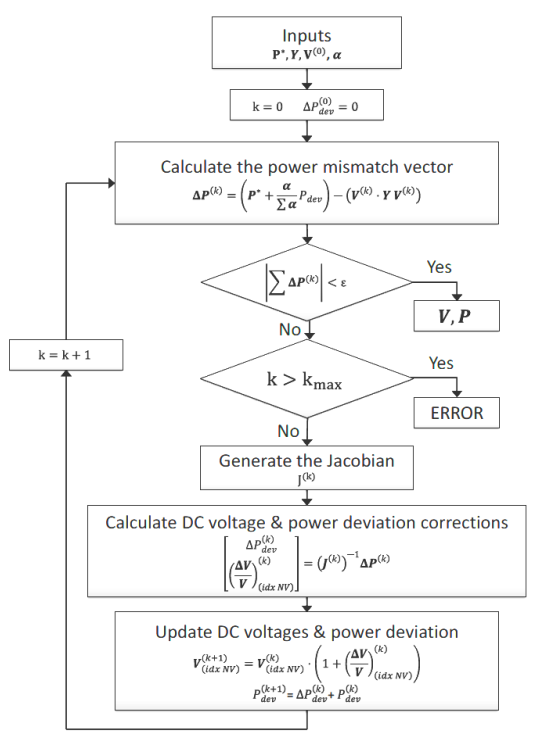

Fig. 12. DC load flow algorithm

1) Normal operation: One day of wind power production is scaled down to the test-bed converter station nominal power. To see the effect if there is no coordinated controller, the same scenario is tested without this controller. For this test, $\mathrm{GS}_{1}$ and $\mathrm{GS}_{2}$ are droop controlled with the droop value set at 0.82 $\mathrm{pu} / \mathrm{pu}$; the power and voltage references of $\mathrm{GS}_{1}$ and $\mathrm{GS}_{2}$ are $0 \mathrm{~W} / 250 \mathrm{~V}$ and $0 \mathrm{~W} / 250 \mathrm{~V}$ respectively. 


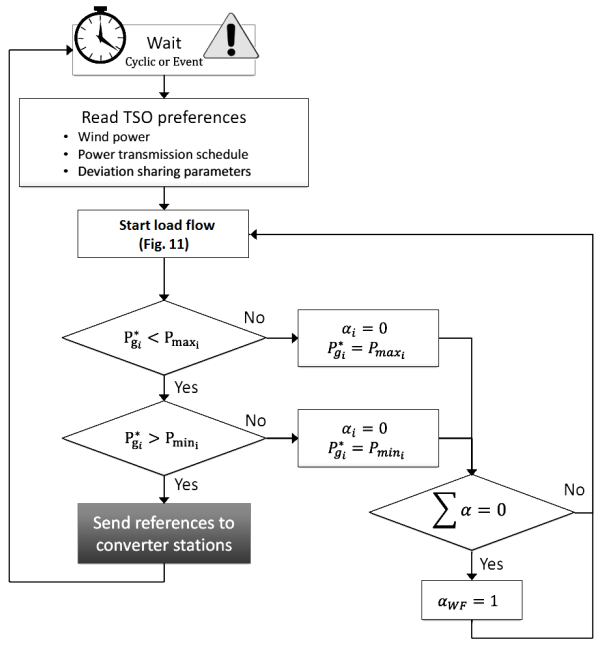

Fig. 13. Coordinated control scheme
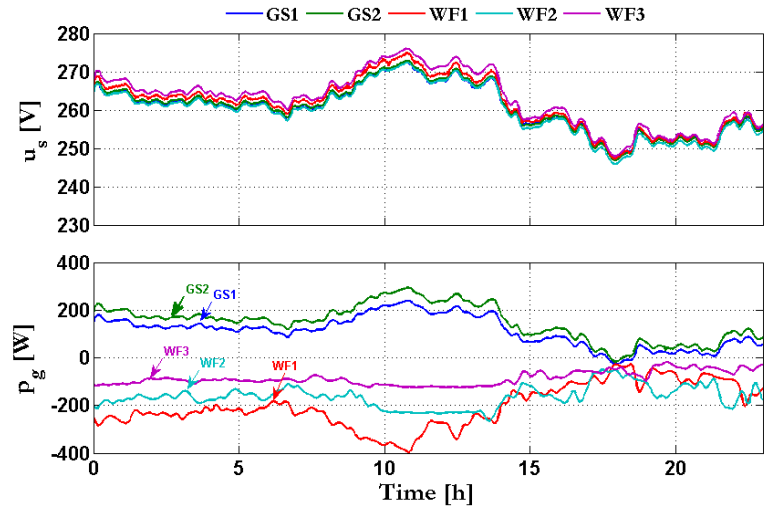

Fig. 14. Experimental results of 1 day of wind power production without coordinated controller

In Fig. 14, the power injected from wind farm stations is shared between $\mathrm{GS}_{1}$ and $\mathrm{GS}_{2}$ thanks to the droop control. The power extracted by $\mathrm{GS}_{2}$ is a bit higher than $\mathrm{GS}_{1}$ because the nominal power of $\mathrm{GS}_{2}$ is slightly higher than $\mathrm{GS}_{1}$. The DC voltage depends on the amount of power injected by the wind farms; the more power there is, the higher the voltage. The DC voltage has already reached $275 \mathrm{~V}$, i.e. $10 \%$ over the nominal voltage, even with a power reduced to $20 \%$.

Now considering a coordinated controller, the converter station references are computed by the Load Flow program with the power sharing capability already presented, which is performed on Matlab ${ }^{\circledR}$ client. The OPC protocol is used for the communication between the SCADA system (PcVue) and Matlab $^{\circledR}$. The Matla $b^{\circledR}$ client retrieves the information available on the SCADA server about: the actual power production of wind farm converter stations, the desired voltage level for $\mathrm{GS}_{1}$ set at $250 \mathrm{~V}$ and the states of each converter station.

Each $5 \mathrm{~s}$ the SCADA system changes a variable to indicate to the Matlab ${ }^{\circledR}$ client that it can start a new load flow. Once the references are calculated, the Matlab ${ }^{\circledR}$ client overwrites the converter set points on the SCADA Server. These set points located on the SCADA server are sent to the converter station each $100 \mathrm{~ms}$; i.e. the communication speed between converter stations and the SCADA system.

The Load Flow program has the DC grid admittance matrix, which corresponds to the DC grid topology with measured resistance. To have a similar effect as the droop control that is defined in per unit, the power sharing coefficients of $\mathrm{GS}_{1}$ and $\mathrm{GS}_{2}$ are not exactly equal since they do not have the same power rating. The sharing coefficients are:

$$
\begin{aligned}
& -\mathrm{GS}_{1}: \alpha_{\mathrm{G} S_{1}}=1 \\
& -\mathrm{GS}_{2}: \alpha_{\mathrm{G} S_{2}}=1.18\left(\alpha_{\mathrm{G} S_{2}}=\alpha_{\mathrm{G} S_{1}} \frac{P_{\mathrm{nGS} 2}}{P_{\mathrm{nGS} 1}}\right) \\
& \text { - } \mathrm{WF}_{1}, \mathrm{WF}_{2} \text { and } \mathrm{WF}_{3}: \alpha_{\mathrm{WF}}=0
\end{aligned}
$$

In Fig. 15, the same wind production profiles are tested with the coordinated controller under the same conditions as for the previous case. Therefore, the new operating points, which are calculated each $5 s$, correspond to time steps of $8 \mathrm{~min}$ if the production profile time scale is considered. The power profiles of grid-side converter stations are similar to the case without a coordinated controller since power sharing coefficients have been chosen to share power in the same way as for the droop control strategy. The main difference is on the DC voltage map, which is very close to the nominal voltage. Every $8 \mathrm{~min}$ the voltage of $\mathrm{GS}_{1}$ returns to the reference value.

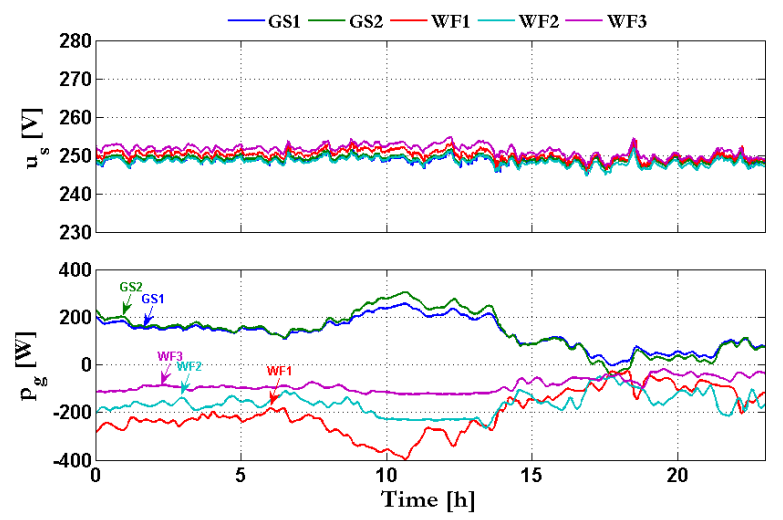

Fig. 15. Experimental results of 1 day of wind power production with coordinated controller

2) Follow-up of the planned grid injection program: The grid-side converter stations can follow a planned AC grid injection program. In Fig. 16, the previous scenario is tested with grid-side power references filled by the injection program $\left(\mathrm{GS}_{1}^{*}\right.$ and $\mathrm{GS}_{2}^{*}$ ). The DC voltage looks like the previous case; it is still close to the nominal value. In contrast to the previous case, grid-side power transfers attempt to follow the scheduled program instead of just sharing part of the wind power production. It is observed that power through grid-side converters is further from the scheduled program than off-line simulation results. This is due to test-bed losses, notably those of physical converters, which are higher in proportion than for the $640 \mathrm{kV}$ test system and are not considered in the creation of the scheduled injection program. Moreover, it should be noticed that the planned injection program is better followed by $\mathrm{GS}_{1}$ than by $\mathrm{GS}_{2}$ since there are more losses in $\mathrm{GS}_{2}$, which is a physical converter, where as $\mathrm{GS}_{1}$ is simulated. 


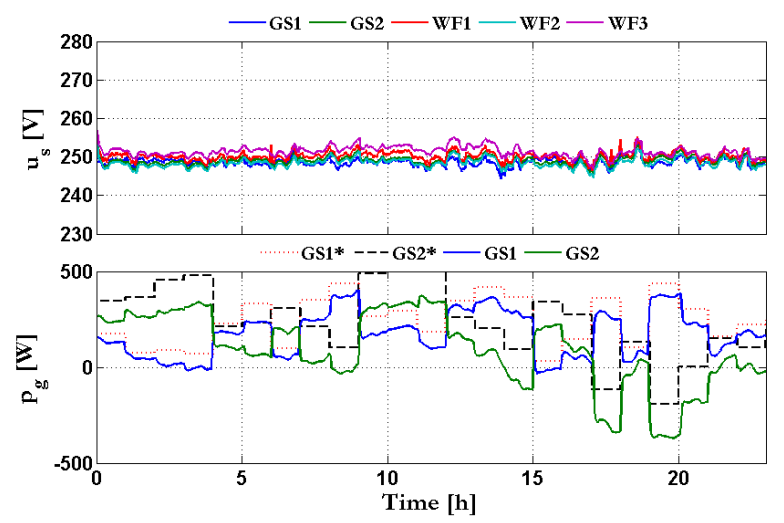

Fig. 16. Experimental results of 1 day of wind power production with coordinated controller using a plan for $\mathrm{AC}$ grid side power injection

3) Alleviation of AC congestion: The advantage of the MTDC-HVDC grid is that the DC system can alleviate AC congestion on the $\mathrm{AC}$ grid request in real time. To assess this functionality, Kundur's grid [16]is connected to the testbed grid-side converter. Fig. 17 shows the general structure of the combined AC-DC system where grid side voltage source converter stations are the links between Kundur's grid and the five-terminal DC grid.

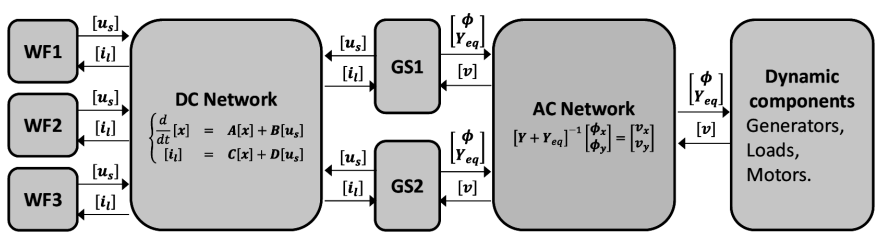

Fig. 17. Block diagram of the AC-DC connected system

The nominal power of $\mathrm{GS}_{1}$ (resp.GS $\mathrm{G}_{2}$ ) converter station is $400 \mathrm{MW}$ (resp. $470 \mathrm{MW}$ ) on the AC side and $2200 \mathrm{~W}$ (resp. $2600 \mathrm{~W}$ ) on the test-bed. The wind production profiles are the same as in previous cases, however this time an $\mathrm{AC}$ grid is connected behind the converter stations. To simulate an overloaded transmission line between the two AC areas, the load located in Area 2 is steeply increased, and in the meantime, the load located in Area 1 is decreased, while generator production is not modified. Once the limit of $300 \mathrm{MW}$ is exceeded between Area 1 and Area $2\left(P_{7-9}\right)$, the supervisor of the AC system asks the SCADA system to quickly change its grid-side power injections in order to induce a $100 \mathrm{MW}$ decrease on the transmission line. To do so, the SCADA system launches a new load flow to compute new converter station set points with power sharing coefficients for $\mathrm{GS}_{1}$ and $\mathrm{GS}_{2}$ (1 and 1.18 respectively); the power references of $\mathrm{GS}_{1}$ and $\mathrm{GS}_{2}$ are set at $-100 \mathrm{MW}(-550 \mathrm{~W})$ and $+100 \mathrm{MW}(+550 \mathrm{~W})$ respectively.

The DC voltage map is not shown in this figure since it is similar to previous cases with a coordinated controller. Power delivered by $\mathrm{GS}_{1}$ and $\mathrm{GS}_{2}$ to the $\mathrm{AC}$ system is equivalent to Fig. 15, until the AC system asks the DC system to change its power flows. To alleviate the AC transmission line between the two areas, there is an offset of $-550 \mathrm{~W}(-100 \mathrm{MW})$ for
$\mathrm{GS}_{1}$ and $+550 \mathrm{~W}(+100 \mathrm{MW})$ for $\mathrm{GS}_{2}$, while power injected by wind farm converter stations does not change Fig. 18. This offset leads to a decrease of $100 \mathrm{MW}$ in the power transmitted through the AC line between the two areas.

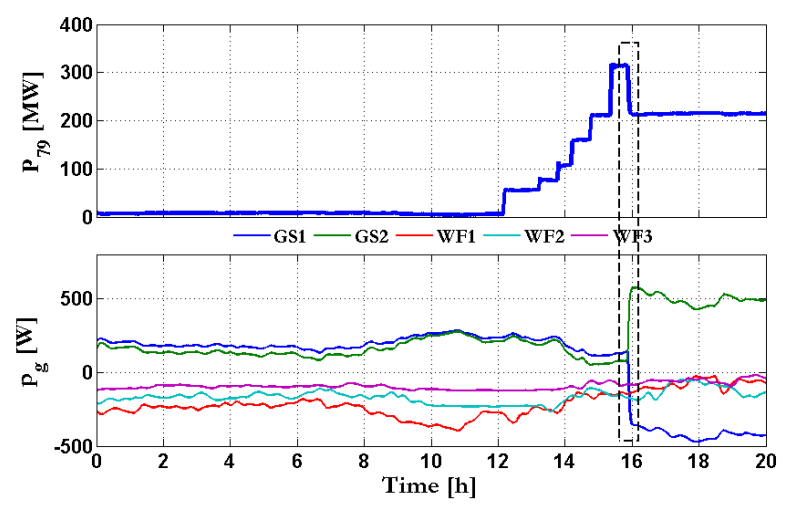

Fig. 18. Experimental results of 1 day of wind power production with coordinated controller- Alleviation of an AC congestion

4) System restoration after a converter outage: It is essential that the coordinated controller can reestablish normal operations after a severe event such as a station tripping. Two tests were carried out to assess this feature; one for an offshore station tripping and another for a grid-side station tripping. For these tests, the primary control strategy is tuned in the same way as in previous cases; grid-side converters are droop controlled, and wind farm converter stations maintain constant power. The coordinated controller updates grid-side converter station references each $5 \mathrm{~s}$, and it is set to share the power harvested by wind farms between $\mathrm{GS}_{1}$ and $\mathrm{GS}_{2}$ in relation to their power rating, like for the previous test without the scheduled program. Before computing new set points, the coordinated controller checks if the converter is operating or not. If the converter is not operating, it is not taken into account in the coordinated control.

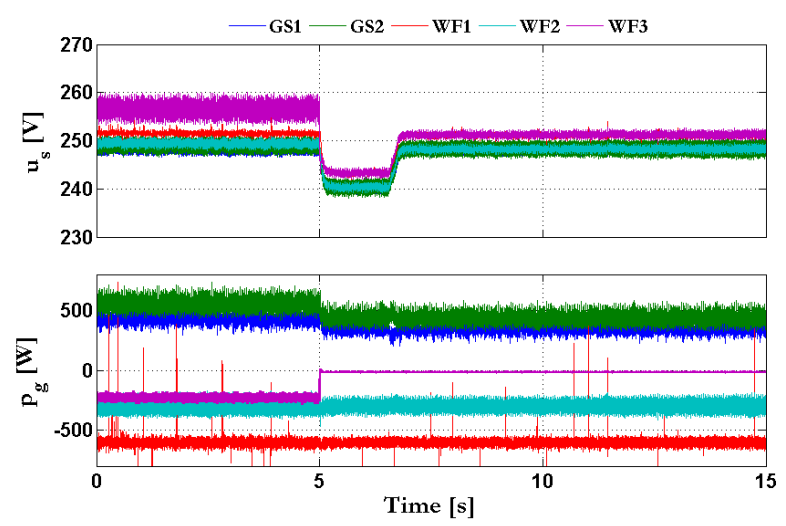

Fig. 19. Outage of a wind farm converter station

In Fig. 19, results of the $\mathrm{WF}_{3}$ tripping test are shown. At $5 \mathrm{~s}$, the $\mathrm{WF}_{3}$ is tripped and the power balance is provided by the two grid-side converter stations which are droop controlled. At about $7 \mathrm{~s}$, the coordinated controller sends new power and 
voltage references to $\mathrm{GS}_{1}$ and $\mathrm{GS}_{2}$. This leads to restoring the DC voltage at nominal value, without any power variation since the power sharing parameters have been set to do the same thing as the droop control power sharing.
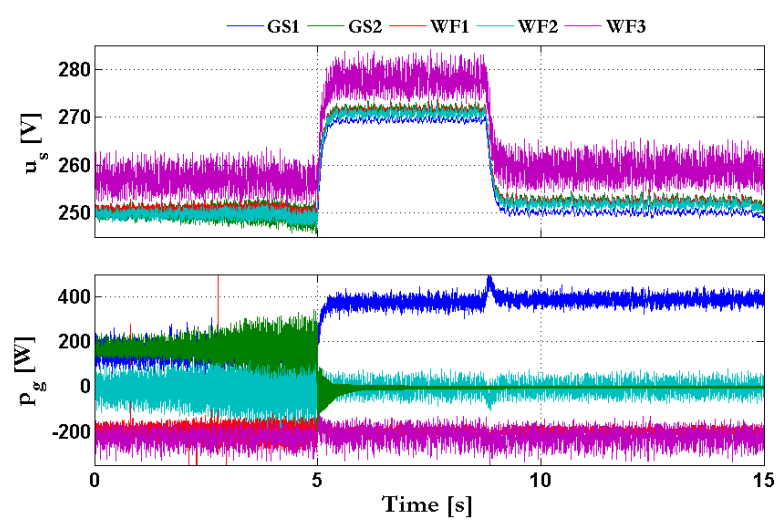

Fig. 20. Outage of a AC grid side converter station

In Fig. 20, results of the $\mathrm{GS}_{2}$ tripping are displayed. For this test, power injection from wind farms has been decreased again to avoid devastating overvoltage when the $\mathrm{GS}_{2}$ is tripped. At $5 \mathrm{~s}, \mathrm{GS}_{2}$ is tripped and all the power which was flowing through it is fully reported on $\mathrm{GS}_{1}$. At around $8 \mathrm{~s}$, the coordinated controller sends new references to $\mathrm{GS}_{1}$, and therefore the DC voltage goes back to the nominal value, and the power delivered by $\mathrm{GS}_{1}$ is almost not impacted.

\section{CONCLUSION}

The objective of this work was to develop a laboratory demonstrator with experimental proof to assess offshore DC grid performance. The tests which are carried out on this testbed are fairly reflective of reality since during the design phase a methodology was set up to have a homothetic laboratoryscale system, and then to represent at best a high voltage grid. The management of the grid is provided by a SCADA system. The demonstrator embeds actual shielded cables which give similar propagation times to actual HVDC cables. Despite excessive voltage drops through cables, the results obtained for droop control on the reduced scale and on the full-scale system exhibit very close dynamics. Also, thanks to a centralized supervisor, it was possible to implement a coordinated control algorithm based on a modified NR algorithm, which is physically independent of the local control. Tests performed with the coordinated controller have shown its effectiveness, either for automatically dispatching power flows or regulating the DC voltage level. As its main contribution, this work has emphasized the DC grid dynamics when it is droop controlled. Also, it has shown the effectiveness of a centralized controller to manage local and independent control without fast communication. On the horizon, the remote control level will be improved to test the behavior in faulty operations. Modular Multilevel Converter (MMC) technology will be integrated instead of classical 2-Level VSC.

\section{REFERENCES}

[1] S. Nguefeu, P. Rault, W. Grieshaber and F. Hassan, "DEMO 3 requirement specifications: detailed specifications for a DC network," TWENTIES deliverable D11.1. April 2012.

[2] "TWENTIES project," TWENTIES, Final report for EWEA, FP7 Twenties project EC-GA n ${ }^{\circ} 249812$, Oct. 2013.

[3] R. Li and X. Wang, "Status and challenges for offshore wind energy," Materials for Renewable Energy \& Environment (ICMREE), 2011 International Conference on, Shanghai, 2011, pp. 601-605.

[4] N. Flourentzou, V. G. Agelidis and G. D. Demetriades, "VSC-Based HVDC Power Transmission Systems: An Overview," in IEEE Transactions on Power Electronics, vol. 24, no. 3, pp. 592-602, March 2009.

[5] J. Beerten, O. Gomis-Bellmunt, X. Guillaud, J. Rimez, A. van der Meer and D. Van Hertem, "Modeling and control of HVDC grids: A key challenge for the future power system," Power Systems Computation Conference (PSCC), 2014, Wroclaw, 2014, pp. 1-21.

[6] S. Shah, R. Hassan and J. Sun, "HVDC transmission system architectures and control - A review," Control and Modeling for Power Electronics (COMPEL), 2013 IEEE 14th Workshop on, Salt Lake City, UT, 2013, pp. 1-8.

[7] Q. Fu, W. Du, J. Cao and H. F. Wang, "VSC-based HVDC power transmission for the large-scale offshore wind power - A survey," International Conference on Renewable Power Generation (RPG 2015), Beijing, 2015, pp. 1-6.

[8] L. Livermore, J. Liang and J. Ekanayake, "MTDC VSC Technology and its applications for wind power," Universities Power Engineering Conference (UPEC), 2010 45th International, Cardiff, Wales, 2010, pp. $1-6$.

[9] L. Xu, L. Yao, and M. Bazargan, "DC grid management of a multiterminal HVDC transmission system for large offshore wind farms," 2009 Int. Conf. Sustainable Power Generation and Supply SUPERGEN, pp. 1-7.

[10] J. Sau-Bassols; E. Prieto-Araujo; O. Gomis-Bellmunt, "Modelling and control of an interline Current Flow Controller for meshed HVDC grids," IEEE Transactions on Power Delivery, vol.PP, no.99, pp.1-1, December 2015.

[11] N. R. Chaudhuri, R. Majumder, B. Chaudhuri and J. Pan, "Stability Analysis of VSC MTDC Grids Connected to Multimachine AC Systems," IEEE Transactions on Power Delivery, vol. 26, no. 4, pp. 2774 2784, Oct. 2011.

[12] E. Prieto-Araujo, A. Egea-Alvarez, S. Fekriasl and O. Gomis-Bellmunt, "DC Voltage Droop Control Design for Multiterminal HVDC Systems Considering AC and DC Grid Dynamics," IEEE Transactions on Power Delivery, vol. 31, no. 2, pp. 575-585, April 2016.

[13] S. Goyal, G. Ledwich and A. Ghosh, "Power Network in Loop: A Paradigm for Real-Time Simulation and Hardware Testing," in IEEE Transactions on Power Delivery, vol. 25, no. 2, pp. 1083-1092, April 2010.

[14] J. Descloux, B. Raison and J. B. Curis, "Protection strategy for undersea MTDC grids," PowerTech (POWERTECH), 2013 IEEE Grenoble, Grenoble, 2013, pp. 1-6.

[15] M. Yang, D. Xie, H. Zhu and Y. Lou, "Architectures and Control for Multi-terminal DC (MTDC) Distribution Network-A Review," AC and DC Power Transmission, 11th IET International Conference on, Birmingham, 2015, pp. 1-7.

[16] P. Kundur, Power system stability and control. Tata McGraw-Hill Education, 1994.

[17] N. R. Chaudhuri and B. Chaudhuri, "Adaptive Droop Control for Effective Power Sharing in Multi-Terminal DC (MTDC) Grids," IEEE Transactions on Power Systems, vol. 28, no. 1, pp. 21-29, Feb. 2013.

[18] E. Prieto-Araujo, F. D. Bianchi, A. Junyent-Ferre and O. GomisBellmunt, "Methodology for Droop Control Dynamic Analysis of Multiterminal VSC-HVDC Grids for Offshore Wind Farms," in IEEE Transactions on Power Delivery, vol. 26, no. 4, pp. 2476-2485, Oct. 2011.

[19] S-A. Amamra, F. Colas, X. Guillaud, P. Rault and S. Nguefeu, "Laboratory-based test bed of a three terminals DC networks using power hardware in the loop," 2013 Power Electronics and Applications (EPE), 15th European Conference on, Lille, pp. 1-8.

[20] "HVDC Light power cables - Submarine and land power cables," ABB, Technical brochure - HVC 2GM5001-gb 3000, Apr. 2006.

[21] P. Rault, "Dynamic Modeling and Control of Multi Terminal HVDC Grid," Laboratoire d'électronique et d'électronique de puissance de Lille, Ph.D. dissertation, March 2014. 
[22] G. Stamatiou and M. Bongiorno, "A novel decentralized control strategy for MultiTerminal HVDC transmission grids," 2015 IEEE Energy Conversion Congress and Exposition (ECCE), Montreal, QC, pp. 57945801.

[23] N. R. Chaudhuri and B. Chaudhuri, "Adaptive Droop Control for Effective Power Sharing in Multi-Terminal DC (MTDC) Grids," IEEE Transactions on Power Systems, vol. 28, pp. 21-29, 2013.

[24] F. Coffele, R. J. Garcia-Valle and E. Acha, "The Inclusion of HVDC Control Modes in a Three-Phase Newton-Raphson Power Flow Algorithm," Power Tech, 2007 IEEE Lausanne, Lausanne, pp. 419-424.

Sid-Ali AMAMRA Was born in Ténès, Algeria. He received the PhD degree in electrical engineering in 2011 from the Versailles University, France. $\mathrm{He}$ is Researcher at the Department of Electrical Engineering of Hautes Etudes d'Ingénieur (HEI) school. He is a member of Laboratory of Electrical Engineering (L2EP), Lille. He is currently working on advanced energy management systems for electrical networks and power systems.

Frederic COLAS Was born in Lille, France, on October 17, 1980. $\mathrm{He}$ received the Ph.D. degree in control systems from Ecole Centrale de Lille, Lille, France, in 2007. Mr. Colas is a member of the Laboratory of Electrical Engineering (L2EP), Lille, and a Research Engineer at Arts et Metiers Paristech. His interests ' include the integration of dispersed generation systems in electrical grids, advanced control techniques for power systems, and hardware-in-the-loop simulation.

Xavier GUILLAUD (M'04) received the Ph.D. degree in electrical engineering from the University of Lille, Lille, France, in 1992. He joined the Laboratory of Electrical Engineering and Power Electronics (L2EP), Lille, in 1993. He has been a Professor with Ecole Centrale of Lille since 2002. First, he worked on the modeling and control of power-electronic systems. Then, he studied the integration of distributed generation and especially renewable energy. These days, he focuses more on the integration of high-voltage powerelectronic converters in the transmission system. He is leading the development of an experimental facility (http://www.epmlab.eu/en/) composed of actual powerelectronic converters interacting with virtual real-time simulated grids. He is involved in several projects about power electronics on the grid within European projects and a large number of projects with French electrical utilities. Prof. Guillaud is a member of the Technical Program Committee of the Power System Computation Conference (PSCC) and Associate Editor of Sustainable Energy, Grids and Networks (SEGAN).

Pierre RAULT Not available.

Samuel NGUEFEU (M'04) received the M.A.Sc. and Ph.D. degrees in electrical engineering from Université Pierre et Marie (Paris VI), Paris, France, in 1991 and 1993, respectively. He was a Consultant for two years before joining THOMSON, Gray, France, in 1996. From 1999 to 2005, he was with EDF R\&D, Clamart, France, in power systems and power electronics. In 2005, he joined the French Transmission System Operator (Réseau de Transport d'Electricité), where he is currently involved in flexible ac transmission systems and HVDC projects. 